Revista Brasileira

de Estudos de

Cinema

e Audiovisual

\title{
O roteirista como escritor, o roteiro cinematográfico como
} literatura $^{1}$

\author{
Maria Castanho Caú ${ }^{2}$
}

${ }^{1}$ Texto apresentado no V Colóquio da Pós-Graduação em Letras da Universidade Estadual Paulista - UNESP, na Faculdade de Ciências e Letras de Assis, em setembro de 2015.

${ }^{2}$ Formada em Cinema pela UFF, mestre e doutora em Literatura Comparada pela UFRJ. Autora do ensaio Olhar o mar - Woody Allen e Philip Roth: a exigência da morte (Editora Verve, 2015). E-mail: mariacau@gmail.com 


\section{Resumo}

O mercado editorial da contemporaneidade parece cada vez mais tentar alavancar vendas apoiando-se na (ainda sólida) popularidade do cinema, essa arte cuja essência, segundo Bazin (1991), funda-se justamente sobre seu caráter radicalmente popular. $O$ apelo comercial da sétima arte a anos impulsiona as vendas dos títulos literários que adapta para as telas do cinema, e o faz com sucesso. Nos últimos anos, a quantidade de livros ligados ao universo do cinema vem se ampliando constantemente, ao mesmo tempo em que os roteiros cinematográficos parecem ter finalmente encontrado seu espaço enquanto gênero literário em expansão. Nota-se que este panomara de construção e popularização de uma nova demanda de leitura, com seus códigos e público específicos, parece ecoar o cenário da popularização das publicações de teatro. Problematiza-se assim o conceito de literatura, pensando de que forma o renovado interesse pela publicação de roteiros representa um reflexo do novo status cultural dessas obras. Através do estudo de caso proporcionado por Four Screenplays of Ingmar Bergman (um dos pioneiros nesse sentido), tentaremos entender as implicações desse novo fenômeno editorial e (re)posicionar o roteirista como autor no âmbito da literatura contemporânea.

Palavras-chave: roteiro; cinema e literatura; Ingmar Bergman.

\section{Abstract}

The contemporary publishing market seems more and more inclined to boost sales by relying on the (still solid) popularity of the cinema, an art whose essence, according to Bazin (1991), is based precisely on its radical popular disposition. The commercial appeal of the seventh art has boosted sales for years, usually of literary titles successfully adapted for the screen. In recent years, the number of books linked to the universe of cinema has expanded steadily, while screenplays seem to have finally found its place as a literary genre in expansion. In this context, a new reading habit is on the way of being stablished, with its specific codes and public, one that seems to echo the scene of the popularization of theater publications. So, in this article we aim to question the concept of literature, analyzing how the renewed interest in the publication of screenplays is a reflection of the new cultural status of these works. Through the case study provided by Four Screenplays of Ingmar Bergman (one of the first volumes of screenplays ever to be published), we try to understand the implications of this new publishing phenomenon and to see the writer as an author in the context of contemporary literature.

Keywords: screenplay; film and literature; Ingmar Bergman. 


\section{Introdução}

É fácil notar que desde seus primórdios o cinema se utilizou dos temas, histórias e personagens da literatura. A via oposta desta influência, ou seja, a literatura usando o cinema, se fez presente desde as primeiras décadas do século $X X$, com o surgimento de edições de livros que almejavam embarcar no já estabelecido sucesso do cinema, ou cujas narrativas dialogavam de alguma maneira com o meio fílmico. Ainda assim, tal via permanece subexplorada. Em Narrativas migrantes: literatura, roteiro e cinema, Vera Lúcia Follain de Figueiredo (2010) faz um breve inventário dessas publicações, demarcando a precoce emergência das versões romanceadas de filmes ${ }^{1}$ e dando destaque à empreitada mais ousada representada pela coleção Cinario, ${ }^{2}$ das edições Gallimard, que já em 1925 "aspirava criar um gênero misto, a meio caminho do roteiro e do romance" (FIGUEIREDO, 2010: 23). O teórico André Bazin (1991) identifica, por sua vez, em 1952, um outro modo de penetração da forma fílmica na literatura, quando admite, por exemplo, que "muitos romances americanos do tipo 'Série noir' são visivelmente escritos com dupla finalidade e em vista de uma possível adaptação por Hollywood" (BAZIN, 1991: 82). Neste sentido, Figueiredo (2010) acrescenta que, à época em que escreve Bazin,

os recursos da linguagem cinematográfica serviram de estímulo ao propósito de renovação do texto literário que tenta escapar da tirania da sequência linear, buscando o efeito de simultaneidade próprio da imagem (FIGUEIREDO, 2010: 25).

\footnotetext{
${ }^{1}$ As famosas novelizações, que parecem ter desaparecido quase por completo. É curioso que o volume de adaptações cinematográficas de títulos literários recentes gera um crescimento exponencial das, então extintas, novelizações.

${ }^{2}$ Assim o site da Gallimard descreve a coleção: "Uma coleção encantadora e conveniente de assuntos especialmente compostos para a tela e concebidos de uma forma que se assemelhe à linguagem cinematográfica" ["Collection aimable et commode de sujets spécialement composée pour l'écran et conçue dans une forme qui s'apparente au langage cinématographique."]. Entre os títulos, encontramse Un suicide, de André Beucler, e Le Roi de la pédale, de Paul Cartoux e Henry Decoin.
} 
Posto isso, não é difícil constatar que o cenário contemporâneo mostra uma ampliação desses entrecruzamentos - com o cinema cada vez mais invadindo o mercado editorial - que tentam se aproveitar do valor agregado do filme, enquanto produto comercialmente valioso, para impulsionar as vendas de uma gama de títulos editoriais. Se as narrativas fílmicas de fato intensificaram sua busca por títulos que possam ser transpostos para a tela - notadamente os best-sellers (em grande parte de perfil juvenil), que atraem um público fiel e cujas adaptações não raro resultam em bilheterias astronômicas,$-{ }^{3}$ o impacto da indústria do cinema no mercado dos livros tornou-se evidente nos últimos anos. Esse intenso intercâmbio promove obras que "tiram partido da popularidade do audiovisual e do prestígio remanescente da cultura livresca, movimentando o mercado editorial" (FIGUEIREDO, 2010: 40).

Nesse contexto, é emblemático que os títulos adaptados para o cinema ganhem, cada vez mais com mais frequência, capas que figuram as mesmas imagens dos pôsteres dos filmes que esses volumes literários inspiraram; fotos promocionais dessas produções; ou alguma referência a elas - tal como, o livro que inspirou o filme. ${ }^{4}$ Além disso, táticas como a elaboração de trailers de livros como estratégia de marketing, e até mesmo a reedição de obras com títulos alterados para coincidirem com aqueles das adaptações fílmicas, sublinham a força dessa inserção. Para Figueiredo (2010), essas práticas configuram

indícios de que o lugar privilegiado na hierarquia cultural, que a modernidade conferia à literatura, vem sendo afetado de maneira significativa, em função

\footnotetext{
${ }^{3}$ São exemplos os livros das séries Harry Potter, Jogos vorazes e Divergente, por exemplo, transpostos para o cinema com grande sucesso comercial.

${ }^{4} \mathrm{O}$ diferencial dos últimos anos é não se tratar apenas de sobrecapas - capas extras de cunho promocional nas quais as edições do passado vinham embrulhadas e embaixo das quais havia uma capa mais sóbria e tradicional - que pareciam cumprir o papel de divulgação ao mesmo tempo em que mantinham a aura do livro como objeto desprendido do filme, e talvez mais elevado que ele. Agora, diferentemente, vemos capas não destacáveis, mesmo os clássicos não escapam à tendência, como é o caso do romance $O$ grande Gatsby, de Scott Fitzgerald, publicado no Brasil simultanemante pelas editoras Landmark e Tordesilhas, ambas em 2013, na mesma época do lançamento da adaptação cinematográfica de Baz Luhrmann (GRANDE, 2013), e com exatamente a mesma capa: o cartaz do filme.
} 
das transformações operadas pelas novas tecnologias da comunicação e pelo protagonismo do mercado na esfera da cultura (FIGUEIREDO, 2010: 44).

Para a autora citada acima, a literatura perde, nesse sistema, sua antes inabalável centralidade, assim como seu caráter canônico de produto final, estável e acabado. E passa a deixar entrever a possibilidade de apropriação de seus elementos por outras searas artísticas. O espaço literário se apresentaria hoje como parte de um processo de trocas e intervenções entre esferas da arte, no bojo do qual emergem novos tipos de texto e outras formas de leitura. Se no passado uma certa cultura literária com frequência rejeitava o cinema, ao tachá-lo como uma diversão frívola e negando-lhe o título de arte, por sua vez, o mercado editorial da atualidade se utiliza justamente desta, outrora rejeitada, popularidade, na busca por alavancar vendas.

\section{$O$ roteirista-autor}

Aqui, o caso da publicação de roteiros cinematográficos, amplamente discutido por Figueiredo (2010), nos fornece um exemplo emblemático. Tal prática, antigamente bastante rara, parece apontar para um novo status dessa forma textual. O roteiro cinematográfico - que deveria ser lido apenas pela equipe do filme na orientação das filmagens, que, por sua vez, daria origem ao produto artístico almejado, o filme -, se converte em narrativa final, e constrói um público de leitores que vai aos poucos se habituando à linguagem própria desse meio, aos seus códigos particulares. Faz-se necessário então questionar: a contemporaneidade atribui ao roteiro cinematográfico a nobre alcunha de literatura, emancipando-Ihe enquanto obra independente? Estaríamos diante de um novo gênero literário? Seriam os roteiristas escritores no senso mais comum da palavra, profissionais a serviço da arte nobre e estabelecida da literatura? Tentando responder a essas perguntas, Figueiredo (2010) aponta que o roteiro ainda se encontra no que ela chama de um entre-lugar, não visto mais apenas como um aparato textual instrumental para a realização da verdadeira obra, o filme, mas ainda sem constituir um gênero literário estabelecido. É fácil perceber essa ambiguidade se pensarmos no caso muito incomum da publicação de roteiros nunca filmados. É certo dizer que tais raras edições se baseiam não apenas na 
excelência do texto em si, e quase que inteiramente na condição célebre de seus autores, em geral não apenas roteiristas, mas também cineastas ou escritores famosos. Nessa categoria encontramos Freud, além da alma - roteiro para um filme (SARTRE, 2005), encomendado por John Houston a Jean-Paul Sartre. O trabalho acabou rejeitado e extensamente modificado. O filósofo não foi sequer creditado na versão final. Um outro exemplo é Babylon revisited: the screenplay (FITZGERALD, 1993), adaptação para a tela grande de um conto de F. Scott Fitzgerald, assinada pelo próprio romancista e jamais filmada. É interessante que, nas últimas linhas da introdução para a edição publicada pela editora norteamericana Carroll \& Graf, o roteirista Budd Schulberg sublinha a importância de Fitzgerald como romancista, parecendo apoiar-se nisso para justificar tal publicação, ao mesmo tempo em que acaba por questionar a relevância das suas incursões na seara do roteiro. Diz ele:

apesar da sua teoria de que o romance ficaria ultrapassado, sendo substituído pela nova arte do cinema, o Fitzgerald romancista vive, enquanto o Fitzgerald homem de cinema permanece como uma quase esquecida nota de rodapé na história literária (FITZGERALD, 1993: 14). ${ }^{5}$

Mais adiante, analisaremos em detalhes um caso pioneiro, o volume Four screenplays of Ingmar Bergman (BERGMAN, 1960), que traz à tona de maneira evidente, esta intricada relação entre a legitimação do roteiro como uma peça de valor literário intrínseco, e seu posto tradicional de material técnico destinado apenas a estruturar e organizar as filmagens, ou seja, sua condição de obra subordinada ao filme.

No momento, devemos partir do entre-lugar de que fala Figueiredo (2010) para compreender o fenômeno do aumento expressivo da editoração de roteiros nas últimas décadas. Mais uma vez é inevitável esbarrarmos na crucial questão da autoria. Nas palavras da ensaísta:

\footnotetext{
${ }^{5}$ Tradução nossa: "despite his theory that the novel would become passé, replaced by the new art of the motion picture, Fitzgerald the novelist lives, while Fitzgerald the movie man remains an almostforgotten footnote to literary history".
} 
A valorização do roteiro como texto, com um valor em si e não apenas como uma ferramenta útil que se abandona após a realização do filme, coloca em pauta questões relativas à autoria da obra cinematográfica e do próprio livro em que se publica o roteiro (FIGUEIREDO, 2010: 40).

Com relação ao cinema, arte coletiva que agrega em seu bojo muitas ações e escolhas artísticas individuais, a noção de autoria parece ter sempre caráter litigioso, envolvendo uma ampla rede de discussões, inclusive políticas (a Política dos Autores proposta pelos Jovens Turcos, as especificidades de produção próprias do grande mercado versus o caso de cinematografias ainda à margem, entre outros casos). Neste ponto, basta apenas frisar que o reconhecimento do roteiro como feito artístico autônomo garantiria ao roteirista o status de coautor do filme, postura ainda pouco presente no espaço da crítica cinematográfica, que na atualidade convencionou conferir a alcunha de autor tão somente ao diretor - e em especial a um certo tipo de realizador. Falamos aqui daqueles que constroem um estilo visual e narrativo reconhecível ao longo de seus trabalhos (novamente, tratase da matriz de que fala Jean-Claude Bernardet (1994) em seu O autor no cinema $)^{6}$, ou que toma para si múltiplas funções, sendo a figura do diretor-roteirista central nesse contexto. ${ }^{7}$

Por ora, para não nos perdermos nesta discussão, é importante colocar que a legitimação de qualquer forma de editoração está intimamente ligada à ideia de autoria (trate-se de literatura, de teatro, de livros de arte e fotografia, por exemplo). Aqui, podemos traçar um paralelo com o caso do advento das publicações de teatro como apresenta Roger Chartier (2002), que fala amiúde da consonância, na

\footnotetext{
${ }^{6} \mathrm{O}$ exemplo mais contundente é o de Alfred Hitchcock, um dos nomes mais prestigiados no contexto da Política dos Autores dos Jovens Turcos, mas que pouco escrevia. A despeito desse fato, é inquestionável que o cineasta imprimia uma marca pessoal em todos os seus projetos - se pensarmos nas suas frequentes e muito imitadas aparições durante os primeiros minutos de seus longasmetragens.

${ }^{7}$ Assim, são considerados mais autorais os projetos de cineastas que também compõem roteiros, ou que além disso tomam para si um número ainda maior de postos. São exemplos atuais Woody Allen (também roteirista e ator), Lars Von Trier (também diretor de fotografia/cinegrafista) entre outros. Novamente, trata-se de uma posição que muitas vezes ignora a centralidade dos produtores (nãodiretores) no esquema do mercado cinematográfico mais estabelecido do mundo: o norte-americano.
} 
Europa do século XVII, entre a lenta emergência da ideia do dramaturgo como o autor por excelência do universo teatral, e o arrefecer da grande resistência dos escritores com relação à publicação de suas peças. O historiador aborda a relutância de Molière e outros autores à editoração de seus trabalhos, assim como o temor desses artistas de que a leitura subtraísse o texto de suas qualidades cênicas, essenciais para a escrita teatral. Quando tanto Molière quanto diversos outros dramaturgos optaram por recorrer aos impressores por conta, principalmente, do expressivo número de cópias piratas de suas peças, mostrou-se capital a preocupação com a busca por um leitor capaz de compreender os códigos próprios do teatro e recriar mentalmente a encenação. Para Chartier (2002), tal apreensão - que ele chama de "o estigma do impresso" (2002: 69) - é patente nas diversas advertências ao leitor presentes em edições do século XVII, sublinhando "a incompatibilidade estética entre o propósito original das peças, escritas para serem representadas, vistas e ouvidas, e a forma impressa, que as privava de sua "vida" (CHARTIER, 2002: 71). Justamente por isso, em diversas dessas tiragens às quais o autor se refere, surgem uma série de marcas de pontuação pouco comuns, ou trechos em destaque, ferramentas utilizadas na tentativa de reproduzir a expressão cênica e a performance oral esperada dos atores.

Neste ponto, o paralelo com as edições de roteiros é bastante claro. Essas vêm em geral acompanhadas de comentários do roteirista ou do cineasta, fotos da produção ou entrevistas, elementos que buscam validar a iniciativa editorial. Ademais, é evidente que, assim como o teatro, a leitura de um texto escrito para o cinema implica a familiaridade com um dado código, e marca uma experiência inteiramente distinta de assimilação. O cinema é um meio profundamente visual, e a distância entre palavra e imagem causa muitas vezes estranhamento ou desconforto àquele que ainda não está acostumado a esse tipo de fruição textual. É nesse sentido que, assim como no caso do teatro, faz-se necessária a construção de uma nova prática de leitura, fato explicitado em diversos dos paratextos destes volumes, e que em parte explica a tentativa de adaptação do formato para algo considerado mais palatável para o leitor comum. Isto é marcante em especial nas edições precursoras, em que se pode constatar a eliminação dos 
termos considerados muito específicos do meio - como alusões a movimentos de câmera e rubricas indicativas de cada sequência, que eram substituídas por indicações mais literárias, ou inteiramente sublimadas -. Pouco a pouco, tais práticas vão sendo abandonadas à medida que o público leitor ganha alguma intimidade com o formato típico dessas obras. Ainda assim, em geral, testemunhamos com mais frequência a publicação de pós-roteiros, em que as cenas não rodadas ou cortadas da versão final são eliminadas e outras cenas são adicionadas; estas, fruto de improvisos no set, ou que, por algum motivo, fugiram do planejamento original. Esta necessidade de conformar perfeitamente roteiro e filme parece indicar a incompletude do processo de emancipação do roteiro, e sua permanência nessa espécie de entrelugar.

Partindo desse contexto é preciso entender que, enquanto experiência de leitura, o roteiro é um texto duro, em geral pouco afeito a quaisquer devaneios poéticos, e que visa à objetividade - de outro modo, obscureceriam-se as demandas de produção e ele perderia seu fundamento original. Quanto maiores as possibilidades interpretativas sugeridas, mais o roteirista se arrisca a não ter suas intenções artísticas compreendidas pela equipe de filmagens - assim, ao primar pela beleza da forma textual ele adentra inevitavelmente um terreno movediço e perigoso, risco não inteiramente contornado quando quem escreve é também o diretor do projeto. ${ }^{8}$ De certa forma, para a escrita de cinema, dificilmente temos um personagem que, por exemplo, caminha por uma ruela triste numa noite melancólica e solitária, mas sim alguém que anda por uma rua escura à noite, cercada de arbustos e vazia. É importante afirmar que esse procedimento de composição de modo algum aponta uma carência do texto de cinema em comparação com o formato romanesco, mas atesta para certas distâncias entre ambos os formatos e as dinâmicas de leitura envolvidas nessa conjuntura.

De fato, o treinamento dos roteiristas muitas vezes envolve esforçar-se para compor um texto que se afaste da linguagem consagrada da prosa literária e prime pela clareza na descrição das ações. Tal necessidade é reforçada à exaustão

\footnotetext{
${ }^{8} \mathrm{O}$ roteiro serve de guia para toda a equipe de filmagens de forma que qualquer ruído em termos de clareza poderia vir a comprometer a comunicação com os tantos profissionais envolvidos.
} 
pelos manuais de roteiro, desde Syd Field (1995) às abordagens recentes, que não se dedicam apenas ao formato clássico-narrativo, flertando também com caminhos que fogem ao modelo tradicional. Assim, exorta Robert McKee (2013), em seu tão bem-sucedido Story, em que discorre sobre o problema da ambição literária para a formação do roteirista. "Quando você achar que escreveu algo particularmente bom e literário, corte" (MCKEE, 2013: 363). Adiante, ele acrescenta, sublinhando de forma um tanto cômica a feição inacabada do texto para cinema:

Pobre do roteirista, pois ele não pode ser um poeta. Não pode usar metáfora e símile, assonância e aliteração, ritmo e rima, os grandes tropos. Em vez disso, seu trabalho deve conter toda a substância da literatura, mas sem ser literário. Um trabalho literário é finalizado e completo dentro de si mesmo. Um roteiro espera uma câmera (MCKEE, 2013: 368).

McKee tem alguma razão. Roteiros são escritos para serem filmados, assim como peças são escritas para serem encenadas. No entanto, o dramaturgo desfruta de um status ainda não alcançado pelo roteirista, e que, se liga à legitimação das suas obras como pertencentes a um gênero literário estabelecido. Estamos, por exemplo, muito mais habituados a questionar e sobrevalorizar a intervenção do cineasta no roteiro, do que a do encenador na peça teatral. ${ }^{9}$ Se o dramaturgo é um personagem central da crítica teatral, no caso do cinema discutese muitíssimo mais o trabalho do diretor do que o labor do roteirista - e quando a crítica fala deste, esboça-se amiúde uma existência flutuante e subordinada -. Não são raros os exemplos de textos da crítica que sequer mencionam o roteirista, e nomes célebres desse ofício, como o de Charlie Kaufman, que é capaz de atrair espectadores para os filmes que escreve, são bastante incomuns. ${ }^{10}$

\footnotetext{
${ }^{9}$ É preciso esclarecer que estamos tratando aqui, principalmente, do caso dos roteiros originais. As adaptações são um caso bem mais complexo nessa rede de intricadas relações entre o cinema e a literatura.

${ }^{10}$ Nota-se que, em relação às séries de televisão, em especial no contexto norte-americano, a situação se inverte por completo: é o roteirista-chefe, criador da série, que, atuando como showrunner, desempenha o cargo de maior poder na estrutura de produção, participando inclusive da contratação dos diretores que atuarão nos espisódios individuais.
} 


\section{Um estudo de caso: Bergman e o roteiro}

Nos termos propostos por McKee (2013), Ingmar Bergman pode ser considerado um roteirista vacilante e incapaz. De seus textos pululam metáforas diversas, descrições que podem parecer desnecessárias, e uma linguagem poética, que é capaz de estimular a imaginação do leitor, guiando-o por um universo fantasmático particular. Bergman enumera matizes de cor para um projeto que pretende filmar em preto e branco; suprime linhas básicas de diálogo (como cumprimentos); transforma em dados concretos o que no filme não passarão de sugestões sutis (o passado ou os hábitos dos personagens, por exemplo); narra imprecisamente ações e reações de atores, ou apresenta recortes de monólogos interiores que não serão de forma alguma encenados, apenas servem para guiar atores (e, por que não dizer, o leitor) em relação às intenções dos personagens. Nos roteiros do autor - e não há dúvidas de que Bergman é considerado um autor de cinema, como já coloca efusivamente Godard (1958) em seu Bergmanorama, artigo publicado na revista Cahiers du Cinéma - não raro surgem descrições como esta, de uma cena de jantar: "Ela levanta sua taça. Vinda do crepúsculo, sem fonte certa, uma melodia é ouvida. Parece ter nascido da noite, do bouquet do vinho, da vida secreta das paredes e dos objetos em torno deles" (BERGMAN, 1970: 70). ${ }^{11}$

Tal descrição de cena retirada de Sorrisos de uma noite de amor, texto presente na aclamada edição americana de 1960, Four screenplays of Ingmar Bergman, é emblemática, pois o roteirista consegue, em um só tempo, descrever um som cuja origem deve ser percebida como desconhecida; aludir a um ambiente externo que não será visto; relatar a experiência aromática proporcionada pelo vinho, a qual o cinema é incapaz de captar e reproduzir. Bergman (1960) constrói uma atmosfera misteriosa e poética que, apesar de bastante alusiva, pouco esclarece os elementos visuais e sonoros em jogo.

Tais procedimentos não são esporádicos na escrita bergmaniana. Em Morangos silvestres (BERGMAN, 1960), também parte do volume mencionado, ele

\footnotetext{
${ }^{11}$ Tradução nossa: "She raises her glass. Out of the twilight, out of nowhere, a melody is heard. It seems to have been born out of the night, out of the bouquet of the wine, out of the secret life of the walls and objects around them".
} 
radicaliza ao escrever um roteiro inteiramente em primeira pessoa, com o narradorpersonagem que reivindica para si a autoria da história que desenrola, expondo suas impressões, frequentemente subjetivas, sensitivas e sentimentais, mas também plenas de lacunas em relação ao desenrolar das ações relatadas, que ocorrem no espaço de um único dia. O personagem Isak Borg inicia seu relato falando de seus preceitos morais, sua opinião sobre si mesmo, seus hábitos, a solidão a velhice, numa confissão íntima que suplanta em muitos os breves trechos de narração em voz-over efetivamente utilizados na versão final. Expressões como "para minha surpresa", 12 "eu ouvi meu coração bater"13 (BERGMAN, 1960: 171), ou "foi um intenso alívio"14 (BERGMAN, 1960: 172), surgem ao longo do texto para delimitar o ponto de vista do protagonista, mesmo que o cinema não se engaje em uma perspectiva única - a exemplo de experiências como aquela de $A$ dama do lago (DAMA, 1947), obra de Robert Montgomery composta de uma série de planos do tipo ponto de vista, apenas gracejos técnicos passageiros.

$\mathrm{Na}$ narrativa de Morangos silvestres (BERGMAN, 1960), Isak evoca seus sentimentos em relação ao ato da escrita, e emergem construções de grande sofisticação, como o momento em que o ex-professor conta o sonho que compõe uma das primeiras sequências do filme, dizendo, "Então tudo aconteceu tão rápida e assustadoramente que mesmo enquanto escrevo isto ainda sinto uma definitiva inquietação"15 (BERGMAN, 1960: 172). O trecho em questão não apenas alude ao momento da escrita, posterior aos eventos, mas problematiza as sensações em jogo no ato de escrever. Já no longa-metragem, Bergman faz uma escolha bastante distinta: a primeira sequência mostra Isak escrevendo em seu escritório, mas se passa no dia anterior ao restante do desenrolar narrativo. Ainda em relação ao texto, há algumas indicações de cena perdidas entre os diálogos que parecem fugir ao domínio do autor Isak, em particular, o momento em que a narrativa assume brevemente o formato de um relato dentro de outro, com Marianne

\footnotetext{
${ }^{12}$ Em inglês: "To my amazement".

${ }^{13}$ Em inglês: "I heard my heart beat".

${ }^{14}$ Em inglês: "It was an intense relief".

${ }^{15} \mathrm{Em}$ inglês: "Then everything happened so quickly and so frighteningly that even as I write this I still feel a definite uneasiness".
} 
contando a Isak seu desentendimento com o marido.

Essas breves considerações já justificariam o interesse do volume de roteiros investigados, e levam-nos a questionar não somente os parâmetros estritos com que delimitamos o formato roteirístico - e aqui não desejamos de forma alguma propor noções de superioridade entre os dois métodos de composição -, mas, se a feição literária dos roteiros de Bergman contribuiu para que ele viesse a ser um dos primeiros cineastas-roteiristas a ter seus textos publicados e aclamados pela crítica especializada. ${ }^{16}$ Há, no entanto, diversos outros pontos de interesse a ressaltar nesta edição pioneira, e que espelham as primeiras experiências editoriais de teatro remontadas por Chartier (2002, 2014). Os paratextos do volume, publicados pela editora Simon \& Schuster, e recheado de stills, esforçamse para validar a iniciativa da impressão. A orelha não assinada, compara Bergman a Shakespeare e assevera que "um filme de Bergman não é um compósito de contribuições de uma variedade de técnicos, mas o produto da força de uma única imaginação e sensibilidade". ${ }^{17}$ Mais além, acrescenta que os textos "mostram que Bergman faz mágica não apenas com câmeras e luzes, mas também com palavras". ${ }^{18}$ É significativo que, em sua tentativa de alçar o diretor ao panteão dos autores literários, o editor anônimo cite justamente o nome de Shakespeare, um dramaturgo e não um romancista, curiosamente também, o primeiro escritor a ser representado pelo cinema como tal. ${ }^{19}$

O prefácio, escrito por Carl Anders Dymlin, produtor dos filmes de Bergman, e na época presidente da Svensk Filmindustri, fala das particularidades de produção e distribuição do cinema sueco, exaltando não apenas o cineasta em questão e a qualidade das tramas que ele compõe, mas todos os profissionais envolvidos

\footnotetext{
${ }^{16}$ Cf. "Bergman as Writer", crítica de Hollis Alpert veiculada na revista Saturday Review de 27 de agosto de 1960

${ }^{17}$ Tradução nossa de: "A Bergman picture is not a composite of contributions from a variety of technicians, but the product of one strong sensibility and imagination".

${ }^{18}$ Tradução nossa de: "[...] they show that Bergman can work magic not only with cameras and lights but also with words".

${ }^{19}$ Como mencionado no filme, hoje perdido, Shakespeare écrivant la mort de Jules César, dirigido por George Méliès, 1907.
} 
nesse sistema de mercado, que Dymlin pormenoriza a fim de demarcar as características distintas que fazem dele o ambiente ideal para o florescimento de uma cinematografia verdadeiramente autoral.

$\mathrm{Na}$ introdução, e à semelhança dos primeiros dramaturgos a se arriscarem a publicar seus trabalhos, Bergman aborda sua relação com a literatura, seu processo de criação de um roteiro, o qual ele qualifica como "uma tarefa quase impossível” ${ }^{20}$ (BERGMAN, 1960: XVI), expressando o desejo por uma notação específica que pudesse dar conta de pôr no papel a estrutura fílmica imaginada, já que, para ele, o roteiro permanece como "uma base técnica um tanto imperfeita" 21 (BERGMAN, 1960: XVII). Adiante, ele fala da separação, para ele radical, entre o cinema e a literatura, que teriam substâncias drasticamente distintas. Por fim, recusa veementemente o título de autor, afirmando:

Pessoalmente, nunca tive a ambição de ser um autor. Não desejo escrever romances, contos, ensaios, biografias, ou mesmo peças de teatro. Quero somente fazer filmes - filmes sobre condições, tensões, imagens, ritmos e personagens que são de uma forma ou de outra, importantes para mim. 0 filme, com seu complexo processo de criação, é a minha maneira de dizer o que quero aos meus contemporâneos. Sou um cineasta, não um autor ${ }^{22}$ (BERGMAN, 1960: XVIII). ${ }^{23}$

Tais elementos discursivos parecem fazer notar uma certa resistência do cineasta à publicação, enquanto os demais paratextos indicam o empenho de

\footnotetext{
20 Tradução nossa de: "[...] an almost impossible task".

${ }^{21}$ Tradução nossa de: "[...] a very imperfect technical basis for a film".

22 Tradução nossa de: "I myself have never had any ambition to be an author. I do not want to write novels, short stories, essays, biographies or even plays for the theater. I only want to make films - films about conditions, tensions, pictures, rhythms and characters which are in one way or another important to me. The motion picture, with its complicated process of birth, is my method of saying what I want to my fellow men. I am a film-maker, not an author".

${ }^{23}$ Não é fora de propósito notar que Bergman certamente escrevia peças de teatro apesar da predileção por encenar textos clássicos, nem que compôs, décadas depois, ao menos dois volumes autobiográficos.
} 
enfatizar a legitimidade da edição. ${ }^{24}$

Em A mão do autor e a mente do editor, Roger Chartier (2014) descreve o processo de desvinculação estrita à cena pelo qual passaram os textos teatrais para que pudessem ser, pouco a pouco, celebrados como literatura. Tratando ainda, da iniciativa editorial da construção do dramaturgo como autor, utilizando muitas vezes o exemplo da trajetória percorrida pelo nome de Shakespeare. Nesta direção, está claro que o reconhecimento pleno do roteirista como autor estaria condicionado a um longo movimento de mudança de mentalidades, cujo desfecho permanece em aberto, com progressos e recuos, que mantêm o roteiro preso ao entrelugar. No entanto, a expansão da publicação de roteiros questiona e rompe o status anteriormente efêmero dessas obras, sendo tal prática um dos costumes editoriais contemporâneos que sinaliza com mais força as novas nuances da relação entre cinema e literatura.

\section{Referências}

ALPERT, Hollis. "Bergman as Writer". The Saturday Review, New York, s.v., p. 2223, agosto, 1960. Disponível em: <https://www.unz.org/Pub/SaturdayRev1960aug27-00022>. Acessado em: 07 de julho de 2015.

BAZIN, André. O cinema: ensaios. Trad.: Eloísa Araújo Ribeiro. São Paulo: Brasiliense, 1991.

BERNARDET, Jean-Claude. O autor no cinema. São Paulo: Brasiliense, 1994.

BERGMAN, Ingmar. Four screenplays of Ingmar Bergman: Smiles of a summer night, The seventh seal, Wild strawberries, The magician. Trad.: Lars Malmstrom e David Kushner. New York: Simon and Schuster, 1960.

CHARTIER, Roger. A mão do autor e a mente do editor. Trad:: George Schlesinger. São Paulo: Unesp, 2014.

Do palco à página: publicar teatro e ler romances na época moderna - séculos XVI-XVIII. Trad.: Bruno Feitler. Rio de Janeiro: Casa da Palavra, 2002.

\footnotetext{
${ }^{24}$ Nas páginas finais do volume, temos a lista cronológica dos filmes de Bergman lançados até então, seguida de um pequeno inventário dos prêmios recebidos por seus títulos. Seguem então duas pequenas biografias: a do cineasta, e dois parágrafos dedicados aos tradutores que converteram o texto a partir dos originais suecos.
} 
DAMA do lago, A. Direção: Robert Montgomery. Roteiro: Steve Fischer. Produção: George Haight. Intérpretes: Robert Montgomery; Audrey Totter; Lloyd Nolan; Tom Tully; Leon Ames e outros. Música: David Snell. Culver City: Metro-GoldwynMayer, 1947. 1 bobina cinematográfica (105 min), son., p\&b, 35mm.

FIELD, Syd. Manual do roteiro: os fundamentos do texto cinematográfico. Trad.: Alvaro Ramos. Rio de Janeiro: Objetiva, 1995.

FIGUEIREDO, Vera Lúcia Follain de. Narrativas migrantes: literatura, roteiro e cinema. Rio de Janeiro: PUC-Rio/ 7Letras, 2010.

FITZGERALD, F. Scott. Babylon Revisited: the screenplay. New York: Carroll \& Graf, 1993.

GRANDE Gatsby, O. Direção e roteiro: Baz Luhrmann. Produção: Bruce Berman. Intérpretes: Leonardo DiCaprio; Joel Edgerton; Isla Fischer; Tobey Maguire; Carey Mulligan e outros. Música: Craig Amrstrong. Burbank: Warner Bros., 2013. 1 bobina cinematográfica (143 min), son., color., 35mm.

GODARD, Jean-Luc. "Bergmanorama: Ingmar Bergman par Jean-Luc Godard". Cahiers du cinéma, Paris, s.v., n. 85, p. 1-5, janeiro, 1958. Disponível em: $<$ http://www.cahiersducinema.com/BERGMANORAMA-Ingmar-Bergman-par.html>. Acessado em: 09 de julho de 2015.

MCKEE, Robert. Story: substância, estrutura, estilo e os princípios da escrita de roteiro. Trad.: Chico Marés. Curitiba: Arte \& Letra, 2013.

MORANGOS silvestres. Direção e Roteiro: Ingmar Bergman. Produção: Allan Ekelund. Intérpretes: Victor Sjöström; Bibi Andersson; Indrig Thulin; Gunnar Björstrand; Julian Kindhal e outros. Música: Erik Nordgren. Solna: Svensk Filmindustri, 1957. 1 bobina cinematográfica (91 min), son., p\&b, 35mm.

SARTRE, Jean-Paul. Freud, além da alma - roteiro para um filme. Rio de Janeiro: Nova Fronteira, 2005.

SORRISOS de uma noite de amor. Direção e Roteiro: Ingmar Bergman. Produção: Allan Ekelund. Intérpretes: Ulla Jacobsoon; Eva Dahlbeck; Harriet Andersson; Margit Carlqvist; Gunnar Björstrand. Música: Erik Nordgren. Solna: Svensk Filmindustri, 1955. 1 bobina cinematográfica (108 min), son., p\&b, 35mm. 